\title{
COMPUTER INTEGRATED MANUFACTURING
}

\author{
Internationale Konferenz über \\ RECHNERINTEGRIERTE FERTIGUNGSSYSTEME
}

Zakopane, March 24-27 1992

jozef KNAPCZYK and Andrzej STEPNIEWSKI"*

- Cracow University of Technology, Cracow, Poland

- "Lublin Academy of Agriculture, Lublin, Poland

SOME EFFECTS OF THE JOINT'S DRIVE SYSTEMS TORSIONAL COMPLIANCES AND THE VELOCITY PROFILES ON THE SR MANIPULATOR'S DYNAMIC ACCURACY

Summary. The dynamic model of the $5 R$ manipulator has been developed and applied for the IRb-60 manipulator. The Lagrange's 2nd order equations for each link are derived including torsional compliances for the 4 th and 5 th joint driven by the steel band transmission systems. The coefficients of the joint drive systems compliances have been calculated on the basis of the static measurement results. The end-effector oscillations measured by using piezoelectric accelerometer are compared with the results of computer simulation. The effects of the jolnt compliances and velocity profiles have been analysed.

\section{i. Introduction}

Usually the fundamental natural (resonance) frequencies of joint drive systems are relatively low $(2+30 \mathrm{~Hz})$, the natural periods $(0,5+0,03 \mathrm{~s})$ are close to the duration of the transient motions associated with regional or local motions (e.g. deceleration of the manipulator arm). Low stiffness(high compilance) values lead to longer stabilization time and reduce performance characteristics esspecially if inertia forces are high, thus reduce accuracy and repetability. For continuous path operations or forcecontroled inspection operations, enhanced compliance is desirable. The best design is one which allows for controlled stiffness and compliance.

Compliant connections effectively increase the number of DOFin addition to degree of freedom for "gross" (programmable) motions, there are degrees of freedom associated with link osclilations relative to their programmed positions. Since equations of manipulator motion are quite complex, the full equations icluding compliance are much more cumbersome. They are also highly nonlinear and contain many coupling terms. However, as it is shown in [4], the compliances of folnts, actuators, and transmission systems, which can be reduced to joints, usually represent $70 \%$ or more of total compliance of manipulator. 
Compliance is an Inherent characteristics of position-controlled robots. The amount of available compllance depends on robot design. Structural compliance can arise due to the stiffness of the manipulator links as well as joint drive systems. The robot arm members are normally quite massive andcan be regarded as rigid links. The bearings and wrist parts are also assumed to be rigid because the jolnt drive systems have quite large torslonaldeflections in comparison [1].

The end-effector compllance characteristics can be derived as a function of manlpulator kinematic and dynamic parameters, and torsional compliance of Individual jolnt. The emerging trend for compliant and light robot with higher payload capacities, and the use of relatively flexlble components of the jolnt drive systems such as steel band transmission strongly suggested that these compliances need to be considered for a realistlc system representation. To apply the compliance model to the robot manipulator the coefflclents of jolnt drive system compliancesare needed. Theoretically these could be obtalned on the basis of the actual drive system specifications. However, since the data for joint drive systems were not avallable from the robot manufacturer it is necessary to measure the compl lances directly [2].

This paper presents the 6R manipulator's dynamic model useful for prediction the end-effector trajectory errors caused by the compliances of the jolnt drive systems. As an example the dynamic model of the IRb-60 manlpulator with the 4th and 5 th joints driven by the steel band transmission systems is analyzed. The measured compliances are used in thls model te describe the dynamic accuracy of the end-effector trajectory.

\section{Trafectory generation}

Usually, it is desirable for the manipulator motion to be smooth with cont1nuous position and velocity for each joint. We can start with trapezoldal velocity function (or line displacement function with two parabolic blends splined together). During the blend portion of the trajectory, velocity profile can be changed according to sine or polymomial functions. We will assume that the blends have the same duration, and therefore the same values of maximum acceleration (modulo a sign).

The blend time and blend range are determined by the peak values of velocity and acceleration according to:

$$
t_{b}=\dot{q}_{\max }, \ddot{q}_{\max }, \quad q_{b}=0,5 \ddot{q}_{\max } t_{b}^{2} \text {. }
$$

The linear portion is described by

$$
q_{11 n}=q_{f}-q_{s}-2 q_{b} \text {. }
$$

If $q_{b} \geq 0,5\left(q_{f}-q_{s}\right)$, then $q_{b}=0,5\left(q_{f}-q_{s}\right), t_{b}=\sqrt{2 q_{b} / \ddot{q}_{\max }}$.

In the case of linear path with parabolic blends (trapezoldal velocity distribution) we can use the following formulas:

$$
\begin{array}{lll}
\text { for } t<t_{s}: q=q_{s} ; & \ddot{q}=0 ; \\
\text { for } t_{s}<t<t_{s}+t_{b}: & \dot{q}=0 ; & \\
q=0.5 \ddot{q}_{\max }\left(t-t_{s}\right)^{2}+q_{s}, & \dot{q}=\ddot{q}_{\max }\left(t-t_{s}\right), & \ddot{q}=\ddot{q}_{\max } ; \\
\text { for } t_{s}+t_{b}<t<t_{f}-t_{b}: & \ddot{q}=0 ; \\
q=\dot{q}_{\max }\left(t-t_{s}-t_{b}\right)+q_{s}+q_{b}, & \dot{q}=\dot{q}_{\max } & \\
\text { for } t_{f}-t_{b}<t<t_{f} & \dot{q}=-\ddot{q}_{\max }\left(t-t_{f}\right), & \ddot{q}=-\ddot{q}_{\max } ; \\
q=q_{f}-0,5 \ddot{q}_{\max }\left(t-t_{f}\right)^{2}, & \dot{q}=0, & \ddot{q}=0 .
\end{array}
$$

In the case oi linear path with sine-type of blends we can use:

$$
\begin{array}{ll}
\text { for } t<t, q=q_{s}, & \dot{q}=0, \\
\text { for } t_{s}<t<t_{s}+t_{b} &
\end{array}
$$




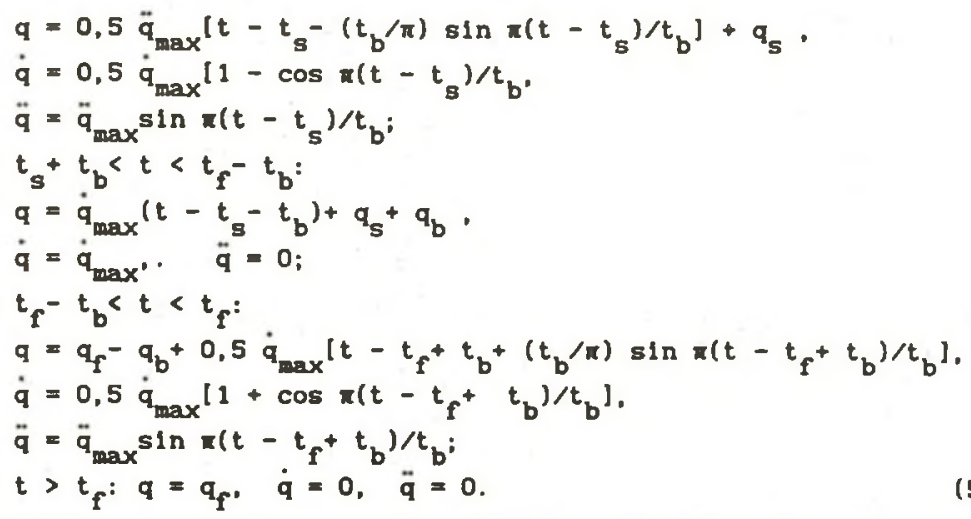

In the case of n-order polynomial type of velocity profile we can use the following formulas:

$$
\begin{aligned}
& q=\sum_{1=1}^{n} \frac{1}{1+1} a_{1}\left(t-t_{s}\right)^{1+1}+q_{s^{\prime}} \\
& \dot{q}=\sum_{1=1}^{n} a_{1}\left(t-t_{s}\right)^{1} \\
& \bar{q}=\sum_{1=1}^{n} 1 a_{1}\left(t-t_{s}\right)^{1-1} .
\end{aligned}
$$

\section{The equations of motions for the manipulator's links}

The equations of wotlons for the 1-th link are derived by using the 2nd order Lagrange 's equation:

$$
\frac{d}{d t}\left(\frac{\partial E_{k}}{\partial \dot{\theta}_{1}}\right)-\frac{\partial E_{k}}{\partial \theta_{1}}+\frac{\partial E_{p}}{\partial \theta_{1}}=M_{1}(t), \quad 1=1+3
$$

If the torsional elasticities in the 4 th and 5 th joints are considered. the equation (7) derived for $i=4$ and $I=5$ can be written in the form:

$$
\frac{d}{d t}\left(\frac{\partial E_{\mathrm{K}}}{\partial \Psi_{1}}\right)-\frac{\partial E_{\mathrm{k}}}{\partial \Psi_{1}}+\frac{\partial E_{\mathrm{p}}}{\partial \Psi_{1}}=M_{1}(t), \quad 1=4,5
$$

where: $E_{p}, E_{k}$ - the potential and kinetic energy of the 1-th 1 ink,

$\theta_{1}$ - the joint angle between the 1-1 and 1-th link,

$\Psi_{1}=M_{1} / K_{1}$ - the torsional deformation defined for the $1-t h$ joint.

$M_{1}$ - the joint drive torque,

$K_{1}$ - the stiffness coefficient of the joint drive system.

The derivation of these equations for the IRb-60 manipulator's link motions together with the detalled descriptions of the used coefficients can be found in the references [2]. The dynamics equations are presented as the joint torque in terms of the joint position, velocity, and acceleration:

$$
\begin{aligned}
M_{1}(t) & =\bar{\theta}_{1} d_{1}+\left(\bar{\theta}_{5}+\bar{v}_{5}\right) d_{2}+\dot{\theta}_{1}\left(\dot{\theta}_{2} d_{10}+\dot{\theta}_{3} d_{11}+\left(\dot{\theta}_{4}+\dot{v}_{4}\right) d_{12}\right)+\left(\dot{\theta}_{7}+\right. \\
& \left.+\dot{v}_{4}\right)\left(\dot{\theta}_{5}+\dot{\psi}_{5}\right) d_{13} . \\
M_{2}(t) & =\bar{\theta}_{2} d_{3}+\bar{\theta}_{3} d_{4}+\left(\bar{\theta}_{4}+\bar{\Psi}_{4}\right) d_{5}-0,5 \dot{\theta}_{1}{ }^{2} d_{10}+\dot{\theta}_{2}{ }^{2} d_{14}+\dot{\theta}_{3}\left(\dot{\theta}_{2}+\right. \\
& \left.+\dot{\theta}_{6}\right) d_{15}+\left(\dot{\theta}_{4}+\dot{\Psi}_{4}\right)\left(\left(\dot{\theta}_{4}+\dot{\Psi}_{4}\right)+2 \dot{\theta}_{6}\right] d_{16}-\dot{\theta}_{1}\left(\dot{\theta}_{5}+\dot{\psi}_{5}\right) d_{13}+C_{2},
\end{aligned}
$$




$$
\begin{aligned}
M_{3}(t) & =\bar{\theta}_{2} d_{4}+\bar{\theta}_{3} d_{6}+\left(\bar{\theta}_{4}+\bar{\Psi}_{4}\right) d_{7}-0,5 \dot{\theta}_{1}{ }^{2} d_{11}+\dot{\theta}_{2}{ }^{2} d_{17}+0,5 \dot{\theta}_{3}\left(\dot{\theta}_{2}+\right. \\
& \left.+\dot{\theta}_{6}\right) d_{18}+0,5\left(\dot{\theta}_{4}+\dot{\psi}_{4}\right)\left[\left(\dot{\theta}_{4}+\dot{\Psi}_{4}\right)+2 \dot{\theta}_{6}\right) d_{19}-\dot{\theta}_{1}\left(\dot{\theta}_{5}+\dot{\Psi}_{5}\right) d_{13}+C_{3}, \\
M_{4}(t) & =\bar{\theta}_{2} d_{5}+\bar{\theta}_{3} d_{7}+\left(\bar{\theta}_{4}+\bar{\Psi}_{4}\right) d_{8}-0,5 \dot{\theta}_{1}{ }^{2} d_{12}-\dot{\theta}_{2}{ }^{2} d_{16}-0,5 \dot{\theta}_{3}\left(\dot{\theta}_{2}+\right. \\
& \left.+\dot{\theta}_{6}\right) d_{19}-\dot{\theta}_{1}\left(\dot{\theta}_{5}+\dot{\Psi}_{5}\right) d_{13}+K_{4} \Psi_{4}+G_{4} \\
M_{5}(t) & =\bar{\theta}_{1} d_{2}+\left(\bar{\theta}_{5}+\bar{\Psi}_{5}\right) d_{9}+\dot{\theta}_{1}\left(\dot{\theta}_{7}+\dot{\Psi}_{4}\right) d_{13}+K_{5} \Psi_{5}
\end{aligned}
$$

where: $\dot{\theta}_{6}=\dot{\theta}_{2}+\dot{\theta}_{3}, \quad \dot{\theta}_{7}=\dot{\theta}_{4}+\dot{\theta}_{6}, \quad \bar{\theta}_{6}=\bar{\theta}_{2}+\bar{\theta}_{3}, \quad \bar{\theta}_{7}=\bar{\theta}_{4}+\bar{\theta}_{6}$, $d_{1}$ - the term of centripedal and Corlolis forces, given in [2]. $G_{1}$ - the gravity tern at the 1-th joint.

\section{Integration of the equations}

The last three equations of the system (9) can be written as

$$
\begin{aligned}
& M_{4}(t)=M_{4 S}+M_{4 D}+M_{4 R} \\
& M_{5}(t)=M_{5 S}+M_{5 D}+M_{5 R}
\end{aligned}
$$

where: $M_{1 S}$ - the static torque caused by gravity loading.

$M_{1 D}$ - the dynamic torque caused by inertia forces.

$M_{1 R}$ - the additional torque caused by elastic oscillations.

By using the eqs $(9)$ and $(10)$ the following relations can be obtained:

$\mathrm{M}_{4 S}=\mathrm{G}_{4}$.

$M_{4 D}=\ddot{\theta}_{2} d_{5}+\ddot{\theta}_{3} d_{7}+\ddot{\theta}_{4} d_{8}-0,5 \dot{\theta}_{1}^{2} d_{12}-\dot{\theta}_{2}^{2} d_{16}-0,5 \dot{\theta}_{3}\left(\dot{\theta}_{2}+\dot{\theta}_{6}\right) d_{19}-\dot{\theta}_{1} \dot{\theta}_{5} d_{13}$,

$M_{4 R}=\bar{\Psi}_{4} d_{8}-\dot{\Psi}_{5} \dot{\theta}_{1} d_{13}+K_{4} \Psi_{4}$,

$Y_{5 D}=\ddot{\theta}_{1} d_{2}+\ddot{\theta}_{5} d_{9}+\dot{\theta}_{1} \dot{\theta}_{7} d_{13}$.

$K_{5 R}=\psi_{5} d_{9}+\dot{\Psi}_{4} \dot{\theta}_{1} d_{13}+K_{5} \Psi_{5}$.

Since the mass center of the grasped object is located at the axis $z_{5}$ of the end-effector, it can be assumed that $M_{56}=0$.

The expressions for the jolnt torques given by equation (11) consist of configuration dependent coefficients multiplied by the instantaneous velocity and acceleration values. Then certain simplifyling geometries are included it is possible also to factorize an expressions into configuration dependent and independent terms. The goal of these simplifications is to reduce the real time computation of the equations [2].

To obtaln the solutions for the manipulator's dynamic equations with time dependent coefficients it is necessary to use numerical integration technique. It was assumed that the torque values in the nelghboring time steps are equal

$$
M_{1}(t)^{n}=M_{1}(t)^{n-1}
$$

The angular acceleration of the oscillation motion in the $n$-th step can be determined by using the following equations

$$
\begin{aligned}
& \bar{\Psi}_{4}=\left(\dot{\psi}_{5} \dot{\theta}_{1} d_{13}-K_{4} \psi_{4}-G_{4}-M_{4 D}+M_{4}(t)^{n-1}\right) / d_{8} \\
& \bar{v}_{5}=\left(-\dot{\psi}_{4} \dot{\theta}_{1} d_{13}-K_{5} \psi_{5}-M_{5 D}+M_{5}(t)^{n-1}\right) / d_{9}
\end{aligned}
$$

The obtained differential equations are 2 -nd order, nonhomogenous with the 
coefficlents dependent on Joint coordinates and their derivat Ives. The numerical integration are performed by using the Runge-Kutta's 4th order wethod modiflcated by GII [2]. To use this method. It is necessary to transform the systen of equations by using the state coordinates

$$
Y_{1}=\Psi_{4}, \quad Y_{2}=\Psi_{5}, \quad Y_{3}=\Psi_{4}, \quad Y_{4}=\Psi_{5}
$$

As a result the system of differential equations of the 1st order is obtained

$$
\begin{aligned}
& d Y_{1} / d t=\left(\dot{\theta}_{1} Y_{2} d_{13}-K_{4} Y_{3}-G_{4}-M_{4 D}+M_{4}(t)^{n-1}\right) / d_{8} \\
& d Y_{2} / d t=\left(-\dot{\theta}_{1} Y_{1} d_{13}-K_{5} Y_{4}-M_{5 D}+M_{5}(t)^{n-1}\right) / d_{9} \\
& d Y_{3} / d t=Y_{1} \quad d Y_{4} / d t=Y_{2}
\end{aligned}
$$

The boundary conditions for the above equations can be presented in the form: $Y_{1}(0)=0, \quad Y_{2}(0)=0, \quad Y_{3}(0)=G_{4} / X_{4}, \quad Y_{4}(0)=0$,

where $Y_{3}(0)$ describes the angle of the elastic torsional deformation (In static condition) of the 4 th Joint drive system at the ipitial point of motion time.

Under assumption (12) the torque value $M_{4}(t)^{n^{-1}}$ is generated for the coordinates and their derivatives calculated in the previous step time. This procedure is provided with an error, and obtalned satisfactory correct results required to reduce the length of the step $t$ ime.

\section{Experimental measurements for the manipulator's comollances}

The torsional stiffness characteristics of the joint drive system are measured by using the test stand with the force and displacement sensors. The recorded results of measurements are linearlzed by using the least square method, so the values of the stiffness coefficlents can be presented (see Table 2).

The acceleration measurements are performed by using the plezo-electric accelerometer DELTA SHEAR-type (Bruel and Kjaer) and recorded by using ENDIM 622.01 (VEB Messapparatenwerk-Schlothelm). The steel cylinder with mass mo, radius $r 0$, and length ho is grasped by the end-effector so that the cylinder symmetry axis is the same as the $x 5$ axis of the end-effector coordinate system. The accelerometer is mounted inside the cylinder hole (Fig.2).

The measurements are recorded only for the torsional oscillations in the 4 th Jolnt drlve system with fixed wrist joint $(\theta 5=0)$, and $f 1 x e d$ arm rotational motion $(\theta 1=0)$. The acceleration profiles recorded for the 4 th joint drive system are presented in Fig.3 (dotted line). The recorded acceleration profile is considered as the sum of tangent acceleration caused by torsional oscillation, and the $x 5$ acceleration component of the end-effector global motion, compared with the computer simulation results.

On the basis of the acceleration proflles, obtained experimentaly, the amplitude of osclilations can be determined (see Flg.4 and 5). The motion along the given trajectory are performed and recorded many times. The angular veloclties are changed step by step with the increment $0,31 / 5$. The extreme values in the middle of the oscillation cycle are recorded when the jolnt torsional velocity is constant.

6. The effects of the compliances in ioint drive systems on the accuracy of the performed trajectory

The effects of the compliances existed in the joint drive systems on the accuracy of the performed trajectory can be presented as the quantitative and qualitative differences obtained with stiff and elastic constraints.

Numerical example 1. The trajectory of the wrist center 03 for the IRb-60 manipulator (see Fig. 1) is given be the following data:

$$
\begin{aligned}
& \mathrm{x}_{03 \mathrm{p}}=1,00 \mathrm{~m} \\
& x_{03 k}=1,60 \mathrm{~m}, \quad t_{p 3}=0 \text {, } \\
& z_{03 p}=0,65 \mathrm{~m} \text {, } \\
& \mathrm{z}_{03 \mathrm{k}}=1,65 \mathrm{~m} \text {, } \\
& v_{03 \max }=0.6 \mathrm{~m} / \mathrm{s} \text {. }
\end{aligned}
$$




$$
\begin{array}{lll}
\theta_{p 1}=-35^{\circ}, & \theta_{k 1}=45^{\circ}, & t_{p 1}=0,1 \mathrm{~s}, \\
\theta_{p 4}=-20^{\circ}, & \theta_{k 4}=-115^{\circ}, & t_{p 4}=0, \\
\theta_{p 5}=-90^{\circ}, & \theta_{k 5}=40^{\circ}, & t_{p 5}=0,05 \mathrm{~s},
\end{array}
$$

where: tpi- the beginning of the motion time at 1-th joint, vouma- the constant velocity of the wrist-center point expressed in the base coordinate system.

The extreme values of the joint torsional oscilations are calculated and shown in the Table 3 . The amplitudes of the torsional oscillationof the 4 th and 5th joint drive systems are obtained as the functionsof the given joint angular velocities. The amplitudes are calculated for 20 different values of velocities with the gradual increments: $0,0785 \mathrm{l} / \mathrm{s}$ (for the 4 th joint), and 0,131 1/s (for the 5 th joint). The computational procedure is repeated 3 times for the following values of the stiffness coefficients: given in the Table 2, decreased by $25 \%$, increased by $25 \%$. The computation results are presented in Fig. 4 and 5 .

The velocity functions of amplitudes computed for the 4 th and 5 th Jolnt drive systems have been quite different. The oscillation motion obtained for the 5th joint is regular, because the mass center of the end-effector with grasped cylinder is located on zs axis, and this oscillation motion is independent on the end-effector orientation. The parameter values of the oscillation motion in the 4th Joint are dependent on the Joint position, velocity, acceleration, and configuration of the manipulator's links. The mean value of amplitude is proportional to the joint velocity.

The natural frequency can be determined from equation (13) transformed into the form:

$$
\begin{aligned}
& \bar{\Psi}_{4} d_{8}-\dot{\Psi}_{5} \dot{\theta}_{1} d_{13}+K_{4} \Psi_{4}=0 \\
& \bar{\Psi}_{5} d_{9}+\dot{\Psi}_{4} \dot{\theta}_{1} d_{13}+K_{5} \Psi_{5}=0 \\
& \text { and } \\
& \nu_{4}=\left(K_{4} / d_{8}\right)^{0,5}, \quad \nu_{5}=\left(K_{5} / d_{9}\right)^{0,5}
\end{aligned}
$$

The numerical results are: $\nu_{4}=8,398 \mathrm{rad} / \mathrm{s}, \quad \nu_{5}=29,393 \mathrm{rad} / \mathrm{s}$.

Table 1. The values of geometrical and mass parameters of the IRb-60 robot manipulator

\begin{tabular}{|l|c|c|c|c|c|c|c|l|}
\hline 1 & 1 & 2 & $2 p$ & 3 & $3 p$ & 4 & 5 & $\mathrm{~d} 1 \mathrm{~m}$ \\
\hline$\alpha_{1}$ & $-\pi / 2$ & 0 & 0 & 0 & 0 & $-\pi / 2$ & 0 & $\mathrm{rad}$ \\
$I_{1}$ & 0,130 & 0,800 & 0,800 & 1,280 & 0,370 & 0 & 0 & $\mathrm{~m}$ \\
$\lambda_{1}$ & 0,800 & 0 & 0 & 0 & 0 & 0 & 0,40 & $\mathrm{~m}$ \\
$\mathrm{~m}_{1}$ & 282 & 220 & 13 & 30 & 143 & 18 & 63 & $\mathrm{~kg}$ \\
$\mathrm{X}_{\mathrm{S} 1}$ & $-0,125$ & $-0,560$ & $-0,400$ & $-0,708$ & $-0,017$ & 0 & 0 & $\mathrm{~m}$ \\
$\mathrm{y}_{\mathrm{S} 1}$ & 0,301 & $-0,050$ & 0 & 0 & 0 & 0 & 0 & $\mathrm{~m}$ \\
$\mathrm{z}_{\mathrm{S} 1}$ & 0 & 0 & 0 & 0 & 0 & 0,041 & $-0,009$ & $\mathrm{~m}$ \\
$I_{\mathrm{X} 1}$ & 45 & 28 & 0,015 & 0,634 & 1,110 & 0,266 & 0,071 & $\mathrm{kgm}$ \\
$I_{\mathrm{y} 1}$ & 37 & 92 & 9,017 & 22,03 & 11,37 & 0,217 & 0,671 & $\mathrm{kgm}$ \\
$I_{z 1}$ & 44 & 105 & 9,024 & 21,62 & 11,24 & 0,152 & 0,646 & $\mathrm{kgm}$ \\
$\theta_{1, \min }$ & -165 & -110 & -110 & 45 & 45 & -165 & -180 & $\mathrm{deg}$ \\
$\theta_{1, \max }$ & 165 & -40 & -40 & 155 & 155 & 30 & 180 & $\mathrm{deg}$ \\
$\dot{\theta}_{1, \max }$ & 1,57 & 1,25 & 1,25 & 1,13 & 1,13 & 1,57 & 2,62 & $1 / \mathrm{s}$ \\
$\bar{\theta}_{1, \max }$ & 2,00 & 3,00 & 3,00 & 3,50 & 3,50 & 4,50 & 4,50 & $1 / \mathrm{s}^{2}$ \\
\hline
\end{tabular}




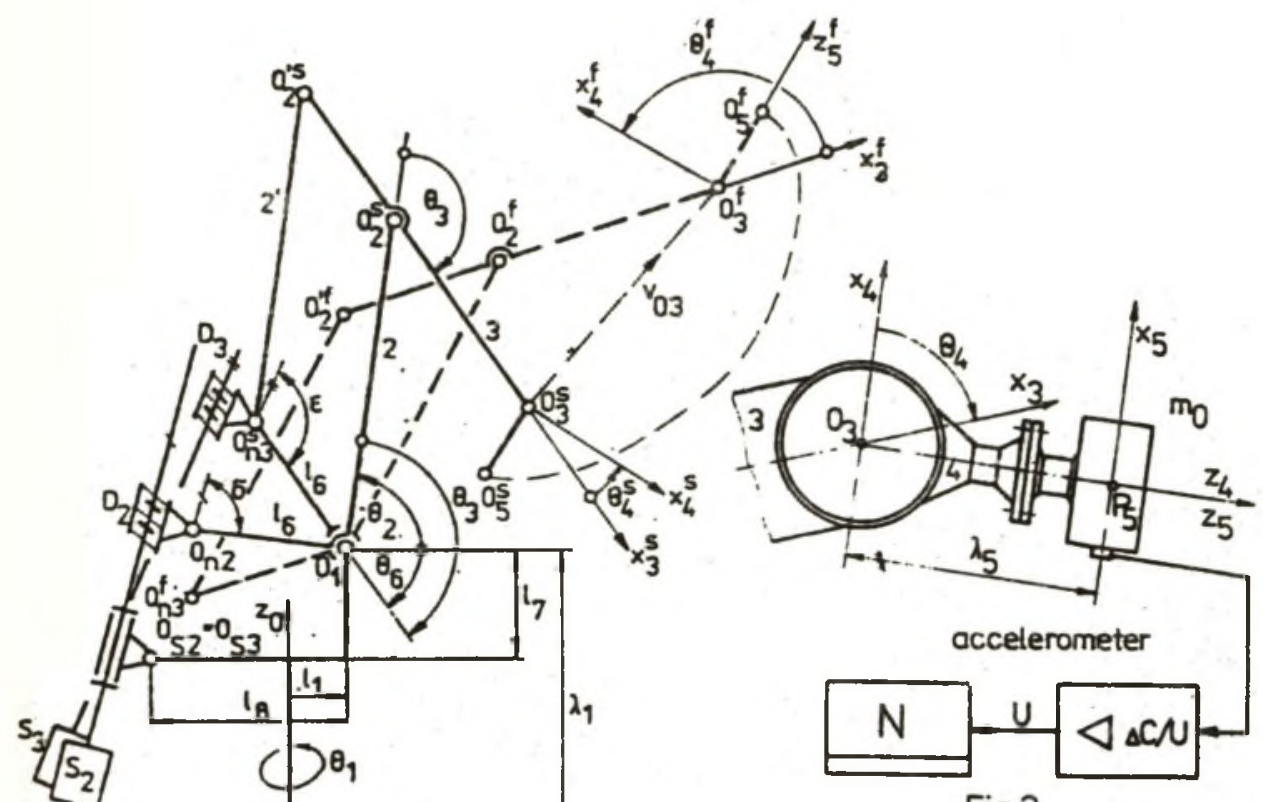

Fig.2.

$v_{4} \mid 10^{-3} \mathrm{rad}$

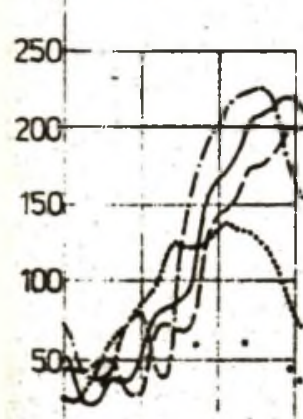

$05-1-\frac{1}{15} \theta_{4}, \mathrm{rod} / \mathrm{s}$

Fig.4.
Fig.3.

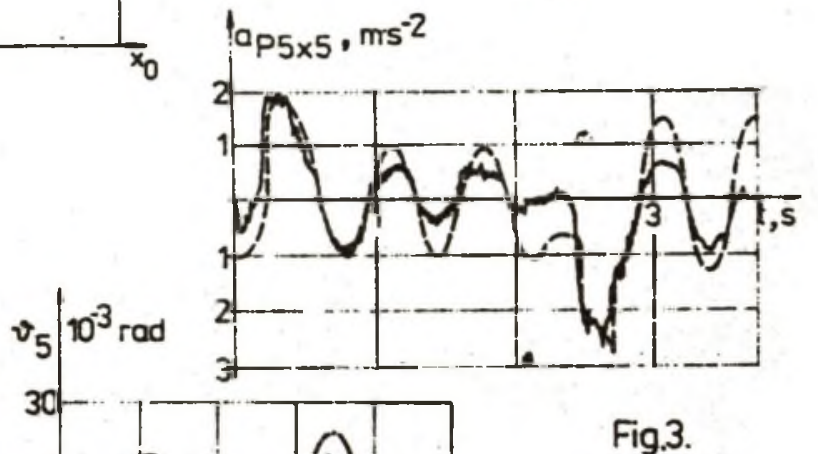

Fig.1.

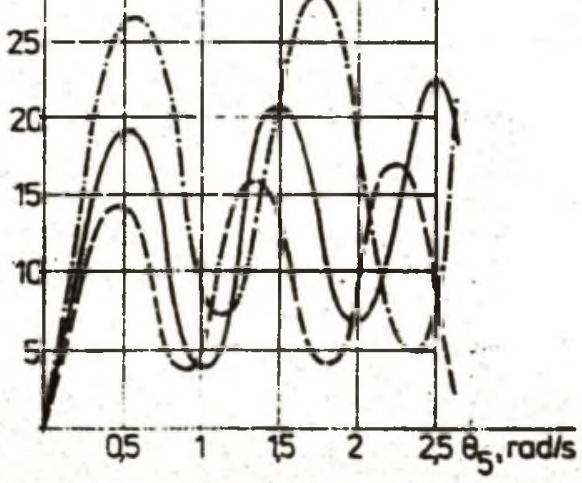

Fig.5. 
Table 2. The st1ffneas coefficients for the IPb-60 robot. Notat 1ons: $K$-the stiffness coefficient, $R$-tbe correlation coefficlent.

\begin{tabular}{|c|c|c|c|c|c|}
\hline & 1 & 2 & 3 & 4 & 5 \\
\hline$K_{1}[\mathrm{Nm} / \mathrm{rad}]$ & 211000 & 346800 & 416100 & 2500 & 22800 \\
\hline$R_{1}$ & 0.9979 & 0.9987 & 0.9978 & 0.9960 & 0.9964 \\
\hline
\end{tabular}

Table 3. The simulation results of the torsional notion parameters

\begin{tabular}{|c|c|c|c|c|c|c|c|}
\hline 1 & \multicolumn{3}{|c|}{4} & \multicolumn{4}{|c|}{5} \\
\hline proflle & trapez & sine & polymon & trapez & sine & pol ynom & dim \\
\hline$m \ln$ & $-0,1548$ & $-0,1439$ & -0.1263 & $-0,0104$ & $-0,0064$ & -0.0052 & rad \\
\hline$\Psi_{1, \max }$ & 0.2622 & 0,2409 & 0.1722 & 0,0091 & 0,0065 & 0.0040 & $\mathrm{rad}$ \\
\hline$\Psi_{1, m i n}$ & $-0,8629$ & $-1,0347$ & -0.4015 & $-0,2511$ & $-0,0958$ & -0.0639 & $1 / s$ \\
\hline$\psi_{1, \max }$ & 1.0834 & 0,9178 & 0.7082 & 0,2519 & 0,0979 & 0.0720 & $1 / \mathrm{s}$ \\
\hline $\bar{\Psi}_{1, \mathrm{~m} 1 \mathrm{n}}$ & $-9,4392$ & $-8,9298$ & -4.6978 & $-7,6962$ & $-2,2352$ & -1.8257 & $1 / s^{2}$ \\
\hline $\bar{\Psi}_{1, \max }$ & 8,4777 & 6,8188 & 4. 5847 & 7,7060 & 2,2056 & 1.3370 & $i / s^{2}$ \\
\hline$\theta_{1}$ & 0,4170 & 0,3848 & & 0.0195 & 0,0129 & & rad \\
\hline
\end{tabular}

\section{Conclusion}

The dunamic model of the $5 R$ manipulator gave us possibllities to study some effects of the conpliances existed in the 4 th and 5 th jolnt drive systems on the performed accuracy for the given end-effector trajectory, and on amplitudes of the torsional osclilations. This model used fur the IRb-60 manlpulator can be userul for another manipulators with the sane kinematic scheme.

The amplitudes of oscillations during acceleration and deceleration motions obtalned from computer sinulation are sufficiently similar to the experimental results. Since the damping was neglected, the calculated results are greater thar in reality.

The mathemat Ical model used for computer slmulation of the manlpulator's dynamics is sufflciently accurate to examine the extreme values of the torsional deflections. The values of amplitudes are proportional to the joint compliances and velacities. These values go up near the resonant frequency. The biggest valises of the joint dynamic torques are followed with the deceleration motion.

Exitation of incremental motions in compliant manipulator drive system is determined by nonlinear comblnations of gross coordinates and their derivat1ves. Magnltudes and slgns of the kinematically linduced components, as well as the overal intensity of the vibratory processes can be modisled by changes in the sequencing of segments in trajectory programing as well as by its location in workspace.

The use of polynomlal or sine-blends tends to reduce the peak deflectlon magnltudes whlle provlding the smoother acceleration time functions.

\section{REFEPENCES}

(1) El Haraghy H. A. Johns B.: An Invest I gation Into the Compl lance of SCARA Robots. Part 1: Analytical Hodel. Part 2: Experimental and Numerical ValidatIon. Trars. ASIF, Jnl of Dynamic Systens, Measurement, and Control, March 1988, v. 110, pp. 18-30.

[2] Stepniewskl A.: Kinematics and Dymanics of the $5 R$ Manipulator with Jolnt Drive System Torsional Elasticities Taking Into Account. Doct. Diss., Cracow Univerelty of Technology. 1989. 
(3) Neganthan G.. Sonl A.H.: Nonlinear Modeling of Kinenatic and Flexibllity Effects in Mnipulator Design. Trans. ASME, Jnl of Mechanisns, Trans. and nut on. In Design, v.110, Sept.1988, pp. 243-254.

[4] Rivin E.J.: Mechantcal Design of Robots. McGraw-H111, N. York 1987.

WPEYW PODATNOSCI SKRETNEJ UKLADOW NAPEDOWYCH PRZEGUBOW MANIPULATORA

MA DOKLADAOSC REALIZOWANEJ TRAJEKTORI I

\section{Streszczenle}

Dla manlpulatore IRb-60 przedstawiono rownania ruchu czlonow przy uwzglednieniu podatnoscl skretneJ ukladow napedowych 4- i 5-go przegubu. Zarejestrowany przebieg przyspleszenla punktu chwytaka porownano $z$ wynikami symulacji komputerowe oraz anallzowano wplyw podatnosci i charakterystyk zadawanego ruchu w przegubach na dokladnosc robota.

EINFLUSS DER DREHEIASTIZITÄT VON ANTRIERSEI EMENTEN DER GELENKEN DES MANIPULATORS AUF DIE GENAUICKEIT DER REALISIERTEN TRANEKTORIE

\section{Zusamenf assung}

Für den Manipulator IRb-60 wurden die Bewegungsglelchungen der Glieder unter Berucksichtigung der Drehelastizitat des vierten und funften Gliedes vorgelegt. Vergllchen wurden: der registrierte und der durch rechnergestatzte Simulation gefundene Verlauf von Beschleunlgung el nes Grelferpunktes. Untersucht wurde Einfluss der Elastizitat und der Elgenschaten von vorgegebener Bewegung in den Gelenken auf die Ganaulgkelt des Roboters.

Wpłyncło do redakcji w styczniu 1992 r.

Recenzent: Jan Kazmierczak 